\section{鈷硅表面复合物存在时 鈷催化剂的表面性質}

关于以硅藻土为担体的合成鉆催化剂中的鈷与硅 的相互作用与催化剂的关系，E. Ries[1] 曾由末还原 的催化剂具有多量小孔隐及較大的表面积說明鉆硅相 互作用的存在。R. Craxford[2]研究了催化剂的还原 卙, 認为鉆硅的作用使催化剂难以还原，而在一定范 四队，难还原的僬化剂有較好的活性。但是鉆硅作用 生成的复合物对催化剂制备及使用过程中的影响則缺 細致的研究。1954 年作者之一曾峦昌研究了鈷催化 部中站硅表面复合物的生成及其含量对于活性的影 响[3]。此后我們㸴究了敍催化剂的表面結构, 由此說 明趠长沉淀时間的鉆催化剂中鈷硅表面复合物含量与

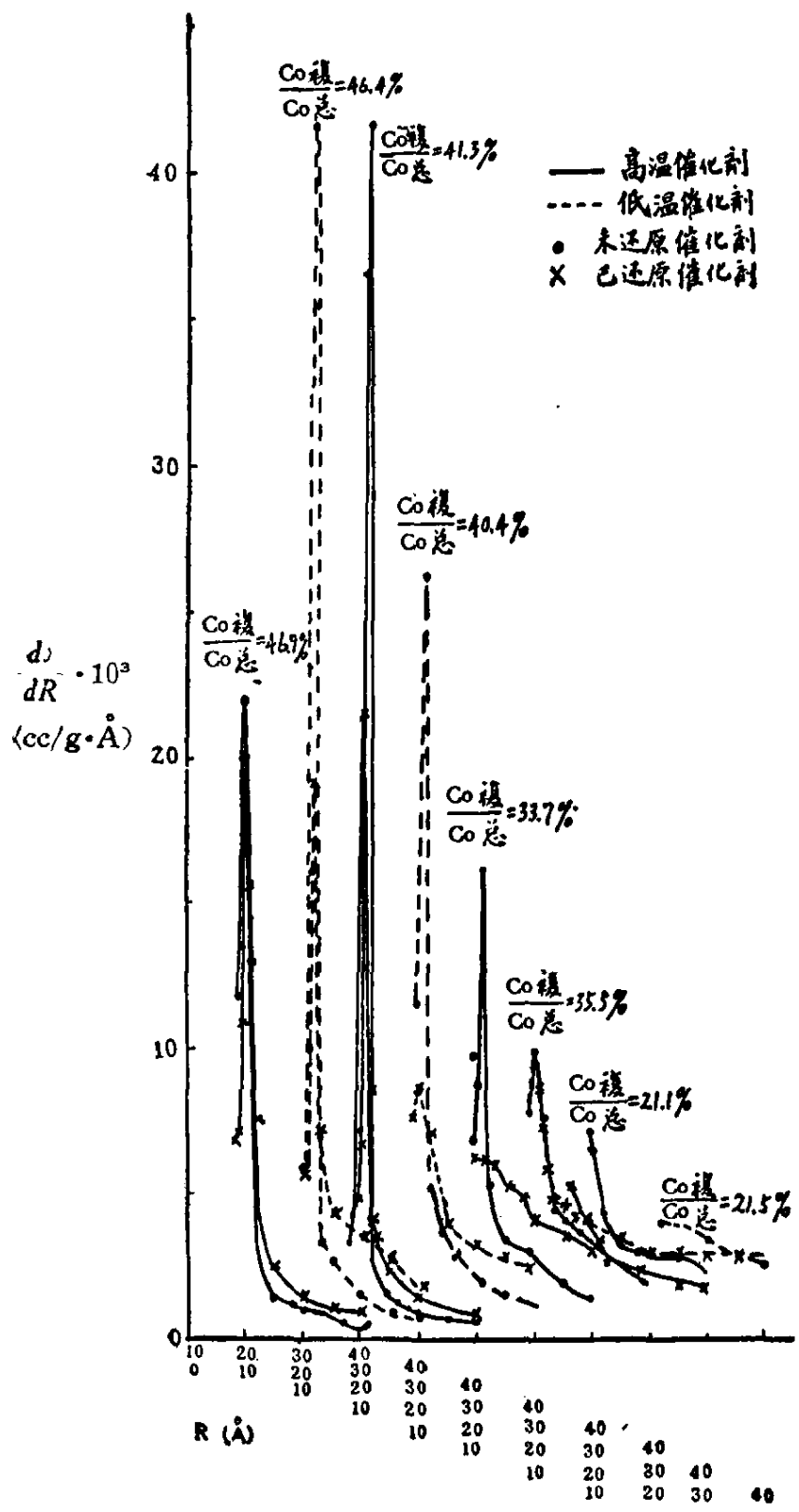

圈 1 Co 催化剂孔弥分布曲綫 - 一孔腺体积 (cc/g), Co 总一催化剂总 Co 量,

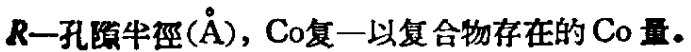

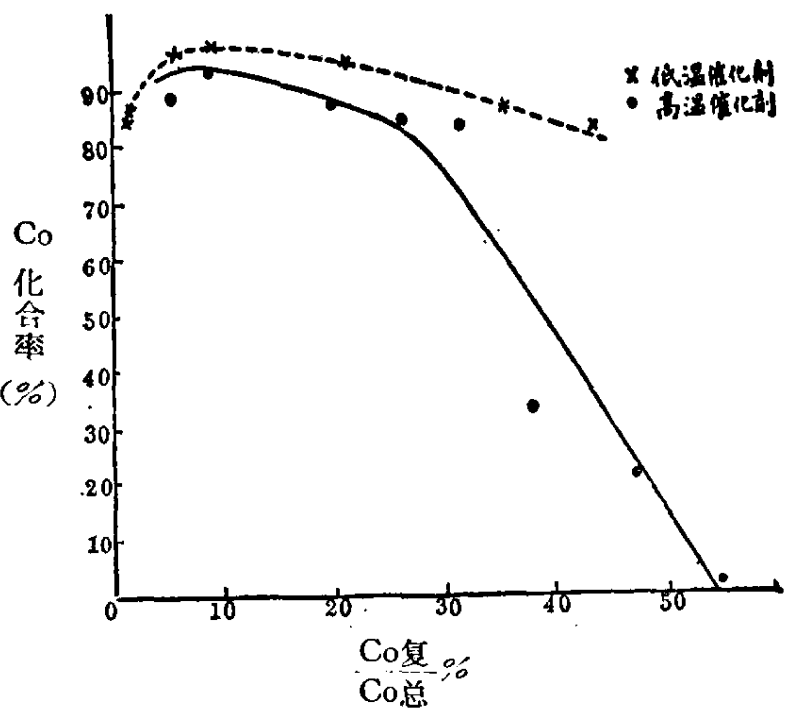

圆 2 鈷硅表面复合物含量与 $\mathrm{Co}$ 化合率的关䒺

活性的关柔 ${ }^{[4]}$ 。最近我們用不同的制备条件，印沵碳 酸鉆与硅藻土的混合温度加以变化, 制成高低温的各 种复合物会量的催化剂来研究其表面結构与活性（混 合温度 $100^{\circ} \mathrm{C}$ 者称为高温, 混合洫度 $93-95^{\circ} \mathrm{C}$ 者为 低温)。發現虽然复合物含量相同的催化剂, 由于制备 时混合温度与时間的不同, 其表面結构及活性皆不相 同 (圖 1、2)。

若 Co 复的百分率为相同时, 高湿制备的銛 催化 剂無論在还原前后，其表面积恒比低温制备者为大， 这是因为高温制备的催化剂其表面孔牛徑为 $20 \AA$ 左 右的孔隙恒較低温制备者为多。还原过程中由于 $\mathrm{Co}$ 复 百分索的大小, 此种孔隙减少程度不同。由各种催化 剂的氮吸附等温綫所計算的孔㗂分布曲䋊(圖 1), 可 看到高温制备的催化剂当 Co复\% 高于 $35 \%$ ，低温催 化剂 Co复\%高于 $40 \%$ 时，还原对于孔隙分布曲綫中 在孔牛徑 $20 \AA$ 时的 $\frac{d v}{d R}$ “最大”减少不多 (高温 Co复 为 $46.9 \%$ 者較特殊, 份在䅗續研究)。如果高温催化剂 Co复\%低于 $35 \%$ ，低温催化剂低于 $40 \%$ 时，則其还 原后的催化剂, 墴論高温或低温, $20 \AA$ 时的 $\frac{d v}{d R}$ “最 大”都比較接近。但在 $10 \times 10^{-3} \mathrm{cc} / \mathrm{g} \AA$ 以下, 高温 者比低温者为大。由于催化剂制备条件的不同，就任温 銛催化剂中 $\mathrm{Co}$ 复 百分事备在此一定范䞍內都具有較 近似量的小孔隙, 而与此相应的高任温还原催化剂都 具有較好的活性, 且低温催化剂的活性恒較活温的好。

\section{張大显 曾秃昌 减景龄 陈 荣}

(中国科学院石油的究所 石油六厂) 1957 年 4 月 5 日

[1] E. Ries. Jr., J. phys. chem., 57,865(1953).

[2] S. R. Craxford, Fuel, Lond., 26,119(1917),

J. Chim. phy., 47,258(1950).

[3] 曾峦昌、刘丰烈、科学通报，1955 年第 10 期, 58 面.

[4] 張大煜等,燃料学报, 2, No.2(1957). 